Research Article

\title{
Thermal Analyses and Responses of Bridge Deck Hydronic Snow Melting System
}

\author{
Junjie Feng $(D)$ and Guansheng Yin \\ School of Science, Chang'an University, Xi'an 710064, China \\ Correspondence should be addressed to Guansheng Yin; yings@chd.edu.cn
}

Received 6 July 2019; Revised 17 September 2019; Accepted 26 September 2019; Published 11 November 2019

Academic Editor: Evangelos J. Sapountzakis

Copyright (c) 2019 Junjie Feng and Guansheng Yin. This is an open access article distributed under the Creative Commons Attribution License, which permits unrestricted use, distribution, and reproduction in any medium, provided the original work is properly cited.

\begin{abstract}
The hydronic snow melting pavement (HSMP) system is an environmentally friendly, clean, and sustainable alternative to traditional approaches for bridge deck snowmelt. The objective of this paper is to investigate the temperature field and thermal responses of HSMP by a three-dimensional finite element (3D FE) model based on the thermal-fluid coupling method. Considering the full fluid domain, the model simulates the dynamic temperature field and obtains the dynamic heat load of HSMP. Results show that the model factually simulates the decrease of fluid temperature along the pipe. The insulation of bridge deck bottom reduces heat loss, and heating demand can be lowered. Due to the ambient temperature changes, preheating is an effective approach of energy conservation and the start time of heating proposed is at 10:00 to 16:00. The flow velocity has a slight influence, and the recommended magnitude is $0.6 \mathrm{~m} / \mathrm{s}$. The shallower pipe embedded depth and the narrower pipe spacing can improve the surface temperature of HSMP and the uniformity of snowmelt process. Under ambient temperature loads, the maximum principle tensile stress of HSMP is induced at the contact interface between pipes and surrounding concrete, and the magnitude is greater than that of the conventional pavement. Under ambient temperature loads and fluid circulation, heated pipes can effectively prevent thermal shrinkage cracking and extend service life of HSMP. With increase of the pipe embedded depth and decrease of the pipe spacing, the chance of thermal shrinkage cracks decreases. For both optimum snowmelt efficiency and thermal cracking reduction, the pipe embedded depth of $7 \mathrm{~cm}$ and pipe spacing of $10 \mathrm{~cm}$ are recommended for HSMP with the inlet fluid temperature of $15^{\circ} \mathrm{C}$.
\end{abstract}

\section{Introduction}

To prevent snow accumulation and ice formation on pavement surfaces and improve traffic safety during winter, the applications of chemical salt are the most common means. As reported, annually nearly 35 million tons of salt was used to melt snow and deice ice worldwide, and this dosage has apparently risen in recent years [1]. However, the usage of salt is ineffective when the ambient temperature falls below $-3.9^{\circ} \mathrm{C}[2]$. Moreover, chemical salt accelerates the deterioration of pavement structure [3], corrosion of steel [4], and pollutes soil and water [5]. As an environmentally friendly, clean, and sustainable alternative, a thermal snowmelt technology can provide one of the solutions [6]. The thermal method includes hydronic pipes $[2,7,8]$, electric heating cables $[9,10]$, and electrically conductive concrete $[11,12]$. Among these three technologies, the hydronic heating system in which the heat is extracted from geothermal, solar energy, and industrial waste heat has received the most attention due to its certain inherent advantages such as the improvement of energy efficiency and reduction in emissions [6, 13].

The hydronic snow melting pavement (HSMP) system is that heated fluid circulates through a series of serpentine or parallel embedded pipes inside the pavement to transfer heat to the pavement and consequently melt snow on the top surface. Therefore, the cleaner and more sustainable hydronic snow melting system has received increasing attention in recent years. Research on the hydronic snowmelt system has been performed since the introduction of the technology in 1948 in Klamath Falls, Oregon, USA [14, 15]. Balbay and Esen $[6,7]$ investigated the feasibility of a ground 
source heat pump system consisting of the vertical type single U-borehole heat exchangers with three different depths $(30 \mathrm{~m}, 60 \mathrm{~m}$, and $90 \mathrm{~m})$ for snow melting on pavement and bridge decks through experiments and the finite element models and obtained congruence between the experimental data and simulations. Liu et al. [16] built a hydronic snowmelt system which could successfully remain the surface snow-free even during severe weather conditions. Rees et al. [17] developed a two-dimensional transient model, and Liu et al. [18] modified the model to simulate a bridge deck hydronic snowmelt system. The modified model could predict the surface temperature and outlet temperature, but the results were slightly higher than the experimental results.

In the open literature, a number of models could predict the surface temperature of hydronic snowmelt pavement, while only a few $[1,13]$ focused on the fluid domain, which was considered as the mean heat output $[19,20]$. The surface temperature was even along the pipe. However, it is untrue since the fluid temperature decreases along the pipe. For the low fluid temperature, the end of the pipe circuit should be controlled according to the lowest surface temperature. It is necessary to develop a model that takes the full $3 \mathrm{D}$ domain into account [21]. The dynamic temperature field of HSMP during all day is influenced by the external climatic conditions. Li and Hong [22] reported the heat load of HSMP obtained from the dynamic temperature field had an effect on the efficiency of snow melt. Therefore, further studies are needed to develop an appropriate control system for the low temperature HSMP system.

The effects of embedded pipes on the mechanical properties of HSMP have been the subject of many studies. Numerical models have been developed and validated by experimental results, which are applicable to perform design with respect to the structural aspect [15]. Van Vliet et al. [23] performed different numerical analyses to quantify the stress and strain in the structural layer, and showed that the shallow depth hollow system could be applied to airfield pavements. Tan et al. [24] compared the responses of traditional versus snowmelt airfield rigid pavement under aircraft loads, temperature loads, and their coupling effects by the means of field tests and a three-dimensional finite element (3D FE) model. The results showed that the embedded pipe did not change the mechanical-induced responses of the pavement. However, there are few reports about the influence of the pipe layouts on the thermal responses of HSMP.

The present paper is aimed to evaluate the effects of heat pipes on the temperature field and thermal responses of conventional pavement and HSMP. Based on the thermalfluid coupling method, a 3D FE model of HSMP was developed by applying ANSYS. The model simulated the dynamic temperature field under ambient temperature and heat pipes and obtained the temperature load of HSMP. In order to obtain the optimal performance of the HSMP system, influence factors such as boundary conditions of the bottom, start time of heating, flow velocity, pipe embedded depth, and pipe spacing on the thermal analyses of HSMP were studied. Simultaneously, the thermal responses of conventional pavement and HSMP were simulated to identify the effects of pipe layout. Finally, the recommended pipe embedded depth and pipe spacing were proposed for the HSMP with the inlet fluid temperature of $15^{\circ} \mathrm{C}$. The study presented would provide theoretical support for the design and application of the bridge deck snow melting system.

\section{Methods}

Aiming to evaluate the effects of the heat pipe on the HSMP temperature distribution and thermal responses, the transient conduction and dynamic heat load are taken into account in the thermal analyses and responses for the low temperature $\left(15^{\circ} \mathrm{C}\right)$ HSMP system. In this study, the thermal-fluid coupling method models the heat conduction between pipes and concrete by applying the thermal-fluid pipe element, which can fully reflect temperature change law of the place near the pipe or far from the pipe and consider temperature changes of the fluid along pipes [25].

2.1. Assumptions of the Model. The model of the HSMP system is performed in pipes and concrete materials for bridge decks. The important assumptions applied in this model are as follows [10, 26]:

(1) The heat transfer process of the hydronic snow melting system is transient

(2) Neglect the thermal contact resistance between different materials

(3) The velocity profile is fully developed within the entire pipe section

(4) Materials are uniform, continuous, and isotropic elastic

(5) The interface between materials is fixed

2.2. Mathematical Model of HSMP. The heat conduction in the surface course is a three-dimensional and transient conduction process. The energy equation in the surface course can be written by using Fourier's law as follows:

$$
\frac{\partial T}{\partial \tau}=\alpha\left(\frac{\partial^{2} T}{\partial x^{2}}+\frac{\partial^{2} T}{\partial y^{2}}+\frac{\partial^{2} T}{\partial z^{2}}\right)
$$

where $T$ is temperature $\left({ }^{\circ} \mathrm{C}\right) ; \tau$ is time (s); $x, y$, and $z$ are the coordinates; $\alpha=\lambda /(\rho c) ; \lambda$ is the thermal conductivity $\left(\mathrm{W} / \mathrm{m} \cdot{ }^{\circ} \mathrm{C}\right)$; $\rho$ is density $\left(\mathrm{kg} / \mathrm{m}^{3}\right)$; and $c$ is the specific heat capacity $\left(\mathrm{J} / \mathrm{kg} .{ }^{\circ} \mathrm{C}\right)$.

Figure 1 shows the heat exchange of the coupled thermal-fluid pipe. The concrete and pipes are simulated by $3 \mathrm{D}$ solid elements and the thermal-fluid pipe element, respectively. The thermal-fluid pipe element includes two primary nodes $(I, J)$ and two supplemental nodes $(K, L)$. The heat convection of the pipe and concrete is simulated by the coupling between the supplemental nodes of the thermal-fluid pipe element and the nodes of the concrete element.

The governing equation for heat transfer and conservation of energy is described as 


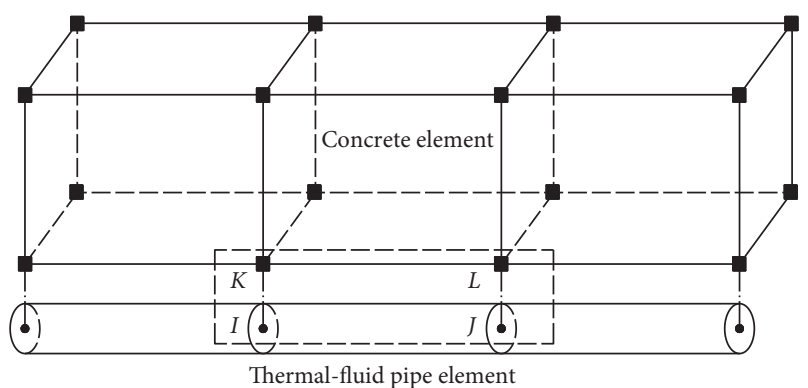

Figure 1: Heat exchange of the coupled thermal-fluid pipe.

$[C]\{\dot{T}\}+[K]\{T\}=\{Q\}$,

$$
\begin{aligned}
{[C] } & =\frac{\rho_{\mathrm{w}} c_{\mathrm{w}} A L}{2}\left[\begin{array}{llll}
1 & 0 & 0 & 0 \\
0 & 1 & 0 & 0 \\
0 & 0 & 1 & 0 \\
0 & 0 & 0 & 1
\end{array}\right], \\
{[K] } & =\left[\begin{array}{cccc}
k_{1}+k_{2}-k_{4} & -k_{1}+k_{4} & -k_{2} & 0 \\
-k_{1}-k_{5} & k_{1}+k_{3}-k_{5} & 0 & -k_{3} \\
-k_{2} & 0 & k_{2} & 0 \\
0 & -k_{3} & 0 & k_{3}
\end{array}\right], \\
k_{1} & =\frac{A \lambda_{\mathrm{w}},}{L}, \quad \text { from } J \text { to } I, \\
k_{2} & =\beta A_{I}, \\
k_{3} & =\beta A_{J},
\end{aligned}
$$

where $[C]$ is the specific heat capacity matrix; $\{\dot{T}\}$ is the node temperature rate vector; $[K]$ is the conduction matrix; $\{T\}$ is the node temperature vector; $\{Q\}$ is the node heat flux vector; $A$ is the cross-sectional area of the pipe; $\rho_{\mathrm{w}}$ is the density of water; $q_{\mathrm{w}}$ is the flow rate of water; $c_{\mathrm{w}}$ is the specific heat capacity of water; $\lambda_{\mathrm{w}}$ is the thermal conductivity of water; $L$ is the element length; $A_{I}=A_{J}=\pi D L / 2 ; D$ is the hydraulic diameter; $k_{4}$ and $k_{5}$ represent the energy changes attributable to the mass transport that is lumped at the outlet nodes, by which the fall in water temperature along the pipe is calculated; $k_{2}$ and $k_{3}$ represent the heat convection of water; and $\beta$ is the convective heat transfer coefficient of water and is calculated by [27].

$$
\mathrm{Nu}=a \operatorname{Re}^{b} \operatorname{Pr}^{c}=\frac{\beta d}{\lambda_{\mathrm{w}}},
$$

where $\mathrm{Nu}$ is the Nusselt number; Re is the Reynolds number, $\operatorname{Re}=d u_{\mathrm{w}} \rho_{\mathrm{w}} / \mu_{\mathrm{w}} ; \operatorname{Pr}$ is the Prandtl number, $\operatorname{Pr}=\mu_{\mathrm{w}} c_{\mathrm{w}} / \lambda_{\mathrm{w}} ; u_{\mathrm{w}}$ is the flow velocity of water; $\mu_{\mathrm{w}}$ is the viscosity of water; and $d$ is the diameter of pipe. According to McAdams [28], $a=0.023 ; b=0.8$; when the fluid is heated, $c=0.4$; when the fluid is cooled, $c=0.3$. There are the service conditions of equation (3), i.e., $\operatorname{Re}=10000-120000 ; \operatorname{Pr}=0.7-120 ; L / d \geq 60$ and the temperature difference is less than $30^{\circ} \mathrm{C}$. In this paper, the outer diameter and inner diameter of the pipe is $0.022 \mathrm{~m}$ and $0.02 \mathrm{~m}$, respectively. The length of the pipe is between 20 $30 \mathrm{~m}$, and the flow velocity of heating water is $0.6-2 \mathrm{~m} / \mathrm{s}$. Thus, we get $L / d=1000-1500, \operatorname{Pr}=7.7$, and $\operatorname{Re}=10909-36364$, which meet the use conditions of equation (3).

2.3. Fluid Temperature Calculations along Pipes. The geometrical model of fluid temperature calculations along the pipe is shown in Figure 2.

In the numerical simulation of fluid-structure interactions, the fluid in heating pipes is considered to be onedimensional steady flow fluid. According to Fourier's law, the heat flux of concrete in contact with pipes is $q=-\lambda(\partial T / \partial n)$. During $\mathrm{d} \tau$, heat exchanges between fluid and concrete (from section $W_{1}$ to section $W_{2}$ ) are expressed as follows:

(1) The heat flux $\mathrm{dQ}_{c}$ of the concrete interface $\Gamma^{0}$ transfers from the fluid and is calculated using the following equation:

$$
\mathrm{d} Q_{c}=-\lambda \iint_{\Gamma^{0}} \frac{\partial T}{\partial n} \mathrm{~d} s \mathrm{~d} \tau
$$

(2) The fluid heat flux $d Q_{W_{1}}$ at the inlet section $W_{1}$ is calculated as follows:

$$
\mathrm{d} Q_{W_{1}}=c_{\mathrm{w}} \rho_{\mathrm{w}} T_{W_{1}} q_{\mathrm{w}} \mathrm{d} \tau
$$

(3) The fluid heat flux $\mathrm{dQ}_{W_{2}}$ at the outlet section $W_{2}$ is calculated by the following equation:

$$
\mathrm{d} Q_{W_{2}}=c_{\mathrm{w}} \rho_{\mathrm{w}} T_{W_{2}} q_{\mathrm{w}} \mathrm{d} \tau
$$

where $T_{W_{1}}$ and $T_{W_{2}}$ are the inlet fluid temperature and outlet fluid temperature, respectively.

(4) The fluid heat flux difference between section $W_{1}$ and section $W_{2}$ is calculated as follows:

$$
\mathrm{d} Q_{W}=\int_{l_{1}}^{l_{2}} c_{\mathrm{w}} \rho_{\mathrm{w}}\left(\frac{\partial T_{w p}}{\partial \tau} \mathrm{d} \tau\right) A_{P} \mathrm{~d} l,
$$

where, $\partial T_{w p}$ is the fluid temperature; $l$ is the coordinate along the pipe; $A_{P}$ is the flow area.

(5) Based on the energy balance, the governing equation is described as

$$
\mathrm{d} Q_{W_{2}}=\mathrm{d} Q_{W_{1}}+\mathrm{d} Q_{c}-\mathrm{d} Q_{W}
$$

The fluid temperature difference $\Delta T_{W}=T_{W_{2}}-T_{W_{1}}$ is calculated as 


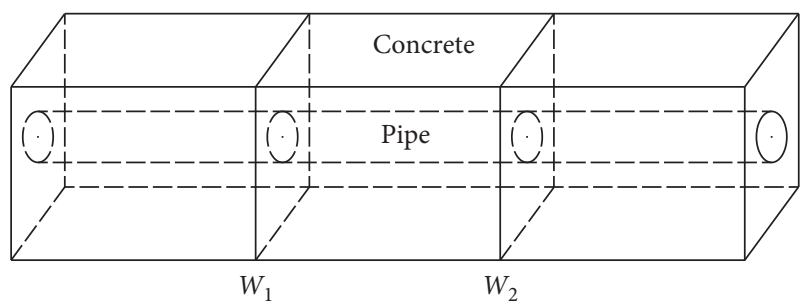

FIGURE 2: Geometrical model of the 3D domain with segments used for fluid temperature calculations.

$$
\Delta T_{W}=\frac{-\lambda}{c_{\mathrm{w}} \rho_{\mathrm{w}} q_{\mathrm{w}}} \iint_{\Gamma^{0}} \frac{\partial T}{\partial n} \mathrm{~d} s+\frac{A_{P}}{q_{\mathrm{w}}} \int_{l_{1}}^{l_{2}} \frac{\partial T_{w p}}{\partial \tau} \mathrm{d} l .
$$

Due to the smaller volume of flows and slight change of fluid temperature, equation (9) is simplified as

$$
\Delta T_{W}=\frac{-\lambda}{c_{\mathrm{w}} \rho_{\mathrm{w}} q_{\mathrm{w}}} \iint_{\Gamma^{0}} \frac{\partial T}{\partial n} \mathrm{~d} s .
$$

The inlet temperature of segments is $T_{W_{0}}$, by which $i$ segment fluid temperature $T_{W_{i}}$ is calculated as

$$
T_{W_{i}}=T_{W_{0}}+\sum_{j=1}^{i} T_{W_{j}}, \quad i=1,2,3, \ldots, n .
$$

2.4. Establishment of the 3D FE Model. The object of this study is shown in Figure 3. In Figure 3(a), serpentine pipes are embedded in the pavement. In Figure 3(b), from top to bottom, the structure of the bridge component is an asphalt layer (AL, $5 \mathrm{~cm}$ in thickness), concreter layer (CL, $13 \mathrm{~cm}$ in thickness), and reinforced concrete body. A point is above the pipe, and $\mathrm{B}$ point is above the centre line between two adjacent pipes. Thermal parameters and elastic parameters of HSMP are shown in Table 1.

A 3D FE model of HSMP was developed to solve the thermal analyses and responses by applying ANSYS. The meshing for the whole model and pipes is presented in Figure 4. The concrete, pipe, and pavement surface (bottom) are modelled by Solid70, Fluid116, and Surf152, respectively. The concrete closest to pipes, where the temperature gradient is steep, are more finely meshed to ensure the temperature and responses to be accurately predicted, as shown in Figure 4(c). The HSMP model domain is the cover area of one of the serpentine pipes (width of $6 \mathrm{~m}$ and length depending on the pipe spacing). Design parameters of pipe layouts are shown in Table 2.

2.5. Weather Data. The temperature field of HSMP is dynamic during the 1st day, which produces the dynamic heating loads. To ensure the efficiency of HSMP, the control design needs to know the conditions of the heating pipes to start. In this paper, the periodic ambient condition was adopted. The air temperature is expanded into periodic functions in the linear combination form of two sinusoidal functions, involving a $24 \mathrm{~h}$ cycle, as shown in the following equation [29]:

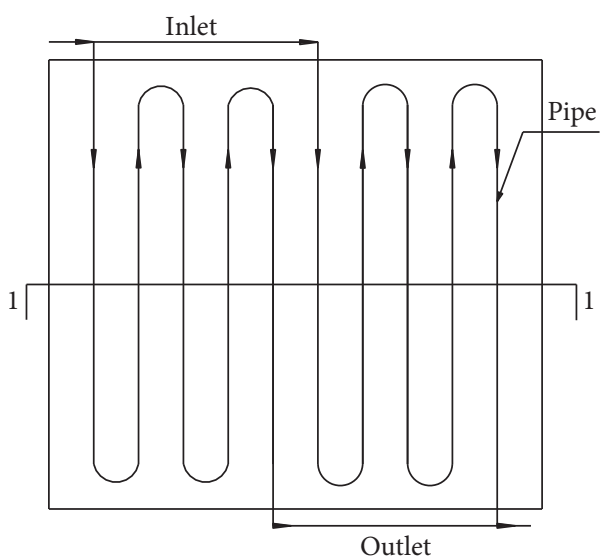

(a)

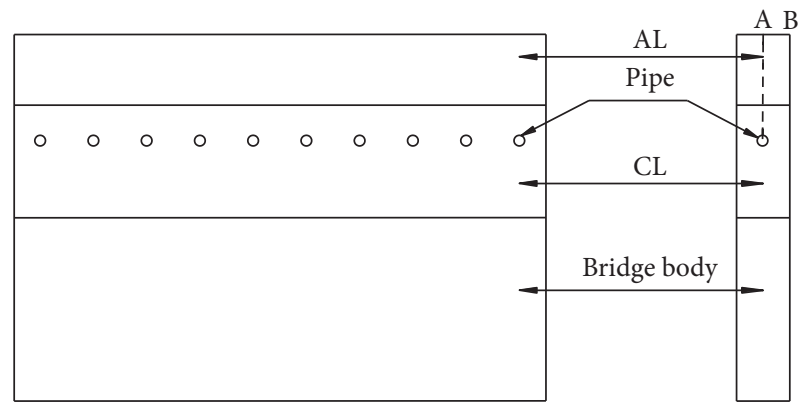

(b)

FIgURE 3: Schematic diagram of HSMP: (a) layout plan; (b) crosssectional view of Section 1.

TABLE 1: Thermal parameters and elastic parameters of HSMP.

\begin{tabular}{lcccc}
\hline Parameter & AL & CL & Pipe & Fluid \\
\hline Material & Asphalt & Concrete & $\begin{array}{c}304 \\
\text { steel }\end{array}$ & Water \\
$\begin{array}{l}\text { Specific heat capacity } \\
\left(\mathrm{J} /\left(\mathrm{kg} .{ }^{\circ} \mathrm{C}\right)\right)\end{array}$ & 1680 & 966 & 467 & 4187 \\
$\begin{array}{l}\text { Density }\left(\mathrm{kg} / \mathrm{m}^{3}\right) \\
\text { Thermal conductivity }\end{array}$ & 2100 & 2450 & 7860 & 1000 \\
$\left(\mathrm{~W} /\left(\mathrm{m} \cdot{ }^{\circ} \mathrm{C}\right)\right)$ & 1.54 & 2.68 & 11.94 & 0.6 \\
$\begin{array}{l}\text { Dynamic viscosity } \\
\left(10^{-3} \mathrm{~Pa} \cdot \mathrm{s}\right)\end{array}$ & - & - & - & 1.1 \\
$\begin{array}{l}\text { Elastic modulus }(\mathrm{MPa}) \\
\text { Poisson's ratio }\end{array}$ & 3000 & 25000 & 206000 & - \\
$\begin{array}{l}\text { Linear expansion coefficient } \\
\left(\times 10^{-5} /{ }^{\circ} \mathrm{C}\right)\end{array}$ & 0.25 & 0.2 & 0.3 & - \\
\hline
\end{tabular}

$$
\begin{aligned}
T= & \frac{T_{\max }+T_{\min }}{2}+\frac{T_{\max }-T_{\min }}{2}[0.96 \sin \omega(\tau-9) \\
& +0.14 \sin 2 \omega(\tau-9)],
\end{aligned}
$$

where $T_{\max }$ is the maximum value of air temperature $\left({ }^{\circ} \mathrm{C}\right)$; $T_{\min }$ is the minimum value of air temperature $\left({ }^{\circ} \mathrm{C}\right) ; \omega$ is the angular frequency, $\omega=\pi / 12 ; \tau$ is the time (s). In the study, $T_{\max }, T_{\min }$, and wind speed are $0^{\circ} \mathrm{C},-5^{\circ} \mathrm{C}$, and $5 \mathrm{~m} / \mathrm{s}$, respectively. Solar radiation, snowfall, and humidity are neglected. 


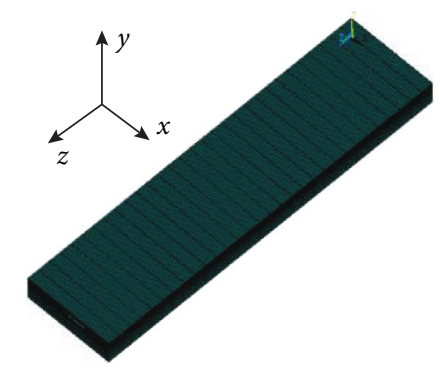

(a)

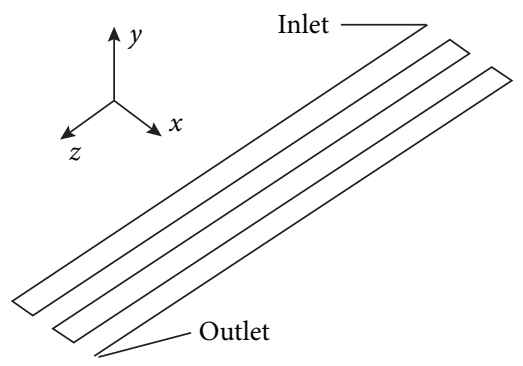

(b)

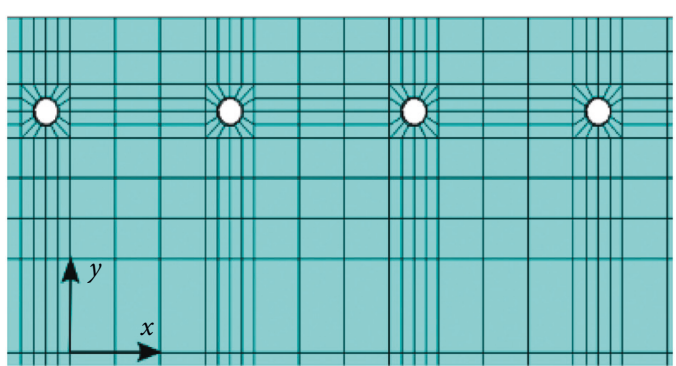

(c)

Figure 4: 3D FE model meshing for: (a) whole model, (b) serpentine pipes, and (c) pipes and surrounding concrete.

TABLE 2: Design parameters of pipe layouts.

\begin{tabular}{lcc}
\hline Parameter & $\begin{array}{c}\text { Parameter } \\
\text { levels }\end{array}$ & $\begin{array}{c}\text { Number of } \\
\text { variations }\end{array}$ \\
\hline Pipe spacing $(\mathrm{cm})$ & $10,15,20,30$ & 4 \\
Pipe embedded depth $(\mathrm{cm})$ & $7,9,11$ & 3 \\
Fluid temperature $\left({ }^{\circ} \mathrm{C}\right)$ & $15,20,25,30$ & 4 \\
Flow velocity $(\mathrm{m} / \mathrm{s})$ & $0.6,1,1.5,2$ & 4 \\
\hline
\end{tabular}

2.6. Boundary Conditions. As reported in Ref. [30], the energy balance at the HSMP surface is related to the atmospheric factors, and the comprehensive heat transfer coefficient is adopted in the study. The sides are adiabatic boundaries [13]. The bottom of CL is adiabatic and convective for HSMP with and without the insulated bottom, respectively.

\section{Results and Discussion}

3.1. Transient Temperature Field of HSMP. This section presents influence of factors (e.g., insulation, start time of heating, flow velocity, pipe embedded depth, and pipe spacing) on HSMP surface temperature distribution. The relationship between surface temperature and factors were analysed.

\subsubsection{Effect of Insulation}

(1) Surface Temperature without Fluid Circulation. The time when the temperature of the model domain becomes periodic is called the transition time. In this study, the calculated transition time of the model domain is $72 \mathrm{~h}$, and the periodic temperature is used as the initial temperature of HSMP. The minimum and maximum temperatures of HSMP without heating are at 6:00 and 16:00, respectively. The heat flux of HSMP is positive from $10: 00$ to $20: 00$, and the other time is negative. The results are in accordance with $\mathrm{Li}$ and Hong [22]. It is necessary to control the heating system to prevent deck surface freezing when HSMP is in a state of heat loss or deck surface temperature is below $0^{\circ} \mathrm{C}$.

Figures 5 and 6 show the temperature field of HSMP with the insulating bottom and of HSMP without the insulating bottom, respectively. The simulated temperature field is similar to the measured data in Ref. [31]. With the insulation at the bottom of HSMP, the HSMP domain temperature gradient in thickness direction is largest near the top surface due to the heat transfer. The maximum temperature difference is about $0.6^{\circ} \mathrm{C}$ regardless of at $6: 00$ and $16: 00$. Without the heat transfer on the bottom of HSMP, the temperature is higher than that of the noninsulated bottom at 6:00. Without insulating the bottom of HSMP, the temperature gradient is steepest near the surface and bottom, respectively. Due to the heat transfer on the surface and the bottom, the maximum temperature difference (approximately $0.3^{\circ} \mathrm{C}$ ) is smaller than that of the insulated bottom, and the temperature is higher than that of the insulated bottom at 16:00.

(2) Surface and Pipe Temperature with Fluid Circulation. HSMP (the pipe spacing of $30 \mathrm{~mm}$ and the pipe embedded depth of $11 \mathrm{~mm}$ ) is heated by the fluid circulation (fluid temperature of $15^{\circ} \mathrm{C}$ and the flow velocity of $0.6 \mathrm{~m} / \mathrm{s}$ ). When the pipes are heated at $6: 00$, it takes $4.25 \mathrm{~h}$ and $4.75 \mathrm{~h}$ to rise to above $0^{\circ} \mathrm{C}$ for the surface of HSMP with the insulated bottom and of HSMP without the insulated bottom, respectively.

Figure 7 indicates the surface temperature (above $0^{\circ} \mathrm{C}$ ) distribution of HSMP. The surface thermal field is approximate to sinusoidal distribution along the $x$ direction and decreases linearly along the pipe. The surface temperature of HSMP without the insulated bottom is lower than that of with the insulated bottom, and it easily generates the stripe phenomena in the snowmelt process. Figure 8 shows the pipe temperature difference between the inlet and the outlet is about $2^{\circ} \mathrm{C}$. Due to the shorter length of the serpentine pipe, the bottom boundary condition has slight effect on the pipe temperature. The optimization of pipe layout is obtained through the $3 \mathrm{D}$ FE model, which can reduce the cost of experiments.

As shown in Figure 9, the heat flux of the insulated bottom gradually increases and remains constant (about $20 \mathrm{~kJ} /\left(\mathrm{h} \cdot \mathrm{m}^{3}\right)$ ) with the fluid circulation, whereas the heat flux of the uninsulated bottom rapidly rises. As Liu et al. [32] reported, conductive and convective heat losses exist at the surface. Temperature difference and wind speed have obvious influences on the heat losses of HSMP. Therefore, insulation can be very important to significantly reduce heat loss, and heating demand can be lowered.

3.1.2. Effect of Start Time of Heating. Due to ambient temperature changes, it is necessary to preheat the HSMP at 


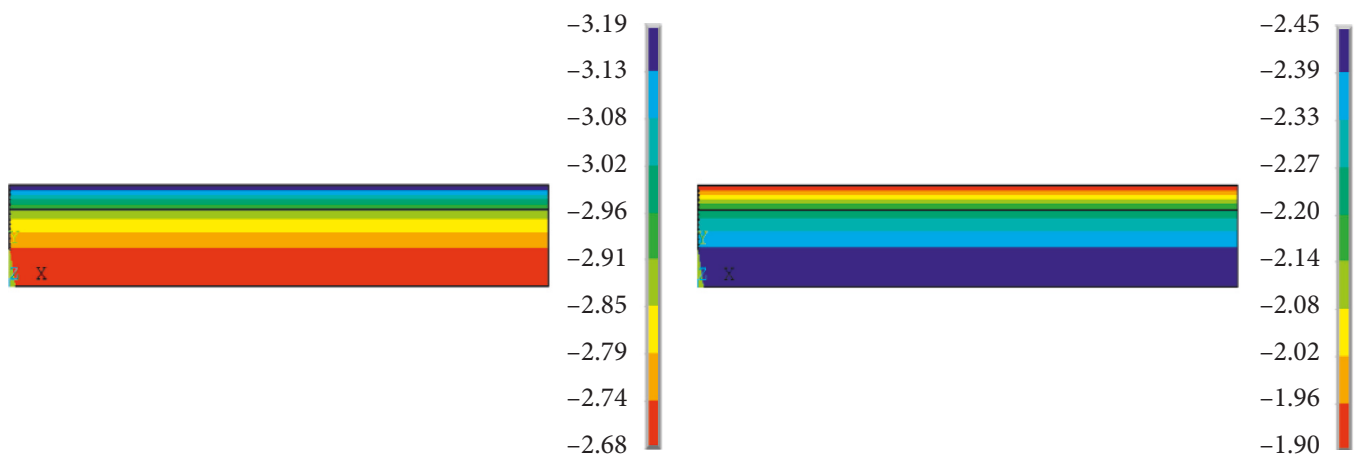

(a)

(b)

Figure 5: Surface temperature distribution $\left({ }^{\circ} \mathrm{C}\right)$ of HSMP with insulating the bottom (a) at $6: 00$ and (b) at 16:00.

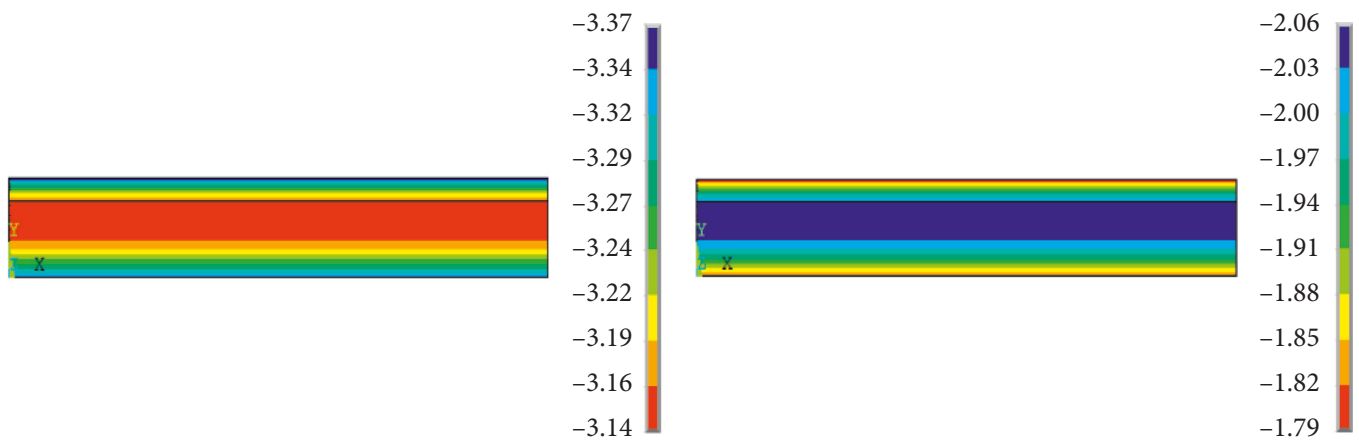

(a)

(b)

Figure 6: Surface temperature distribution $\left({ }^{\circ} \mathrm{C}\right)$ of HSMP without insulating the bottom (a) at $6: 00$ and (b) at 16:00.

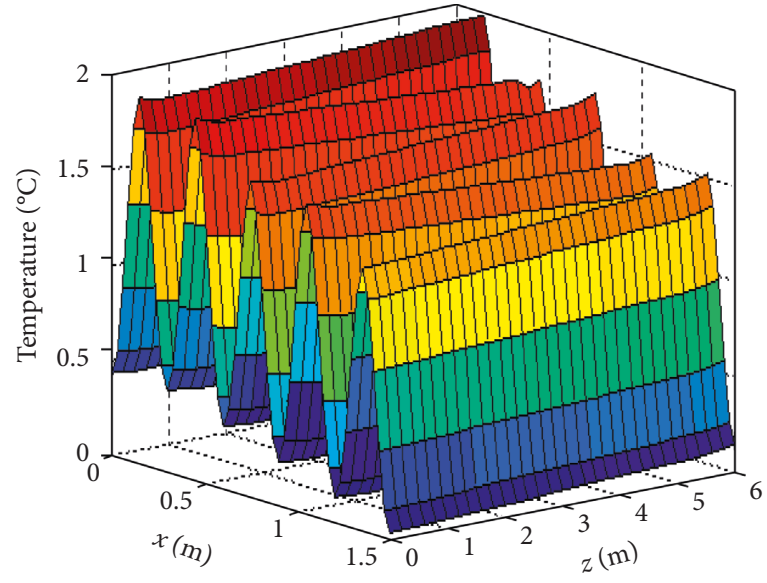

(a)

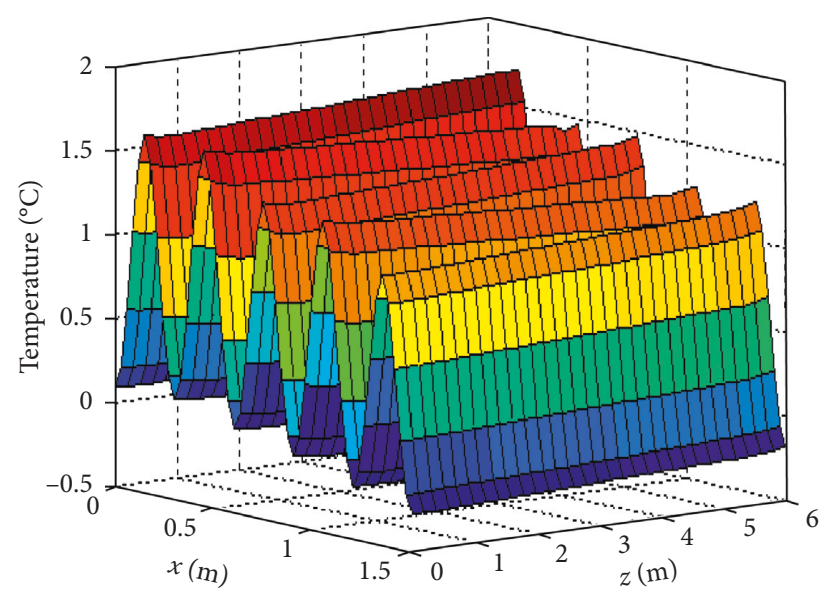

(b)

FIGURE 7: Surface temperature distribution of HSMP: (a) with insulating the bottom; (b) without insulating the bottom.

an approriate time for satisfactory snowmelt effect, and it is an effective approach of energy conservation. As $\mathrm{Hu}$ [33] reported, HSMP obtained more energy and made great impact on snowmelt through proper preheating. The hours required for the surface temperature above $0^{\circ} \mathrm{C}$ when $\mathrm{HSMP}$ is heated at different points in time are presented in Figure 10. The curve is approximate to the cosine function. The hours at $22: 00$ to 4 : 00 is more than that of other points in time. The heating hours at $4: 00$ to $10: 00$ constantly decrease with the rise in ambient temperature. The heating hours at 10:00 to 16:00 is least $(3.5 \mathrm{~h})$. The heating hours at 16:00 to 22:00 gradually increase with the drop in ambient temperature. Therefore, the start time of heating proposed is at 10:00 to $16: 00$.

3.1.3. Effect of Flow Velocity. The fluid is turbulent and meets equation (3) when the flow velocity is greater than the critical 


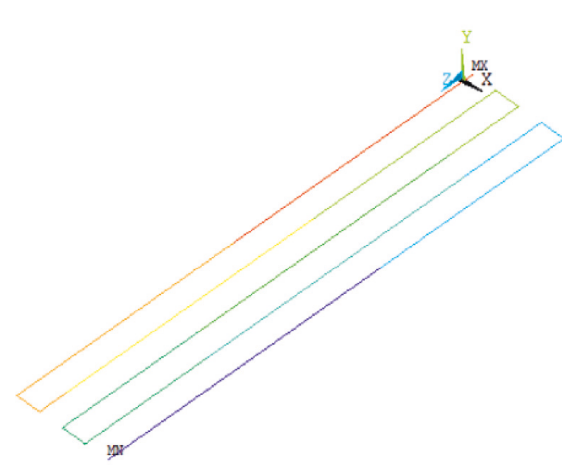

(a)

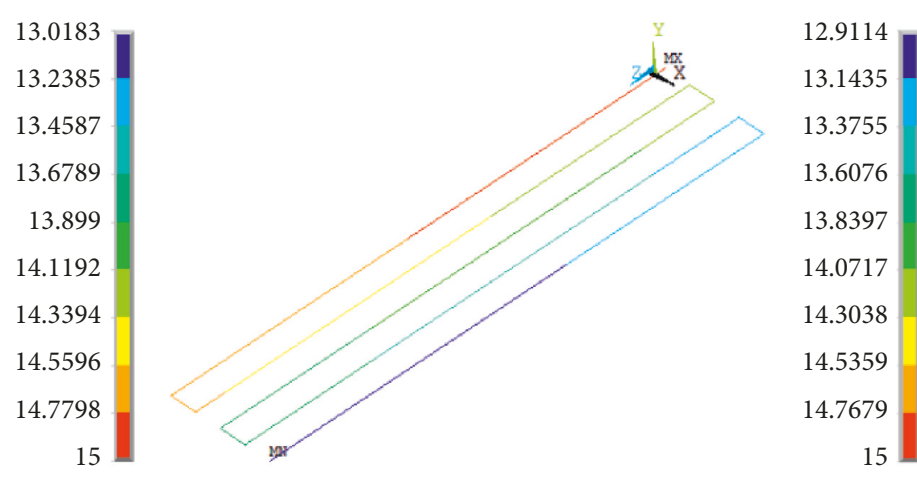

(b)

FIgURE 8: Pipe temperature distribution $\left({ }^{\circ} \mathrm{C}\right)$ : (a) with insulating the bottom; (b) without insulating the bottom.

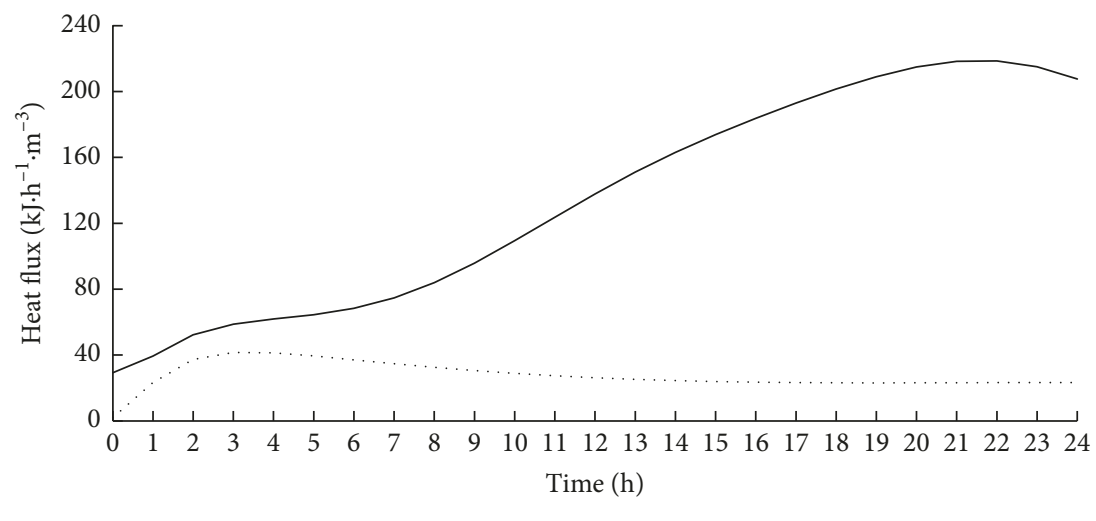

Noninsulated bottom

- Insulated bottom

Figure 9: Heat flux of the bottom time-history curve.

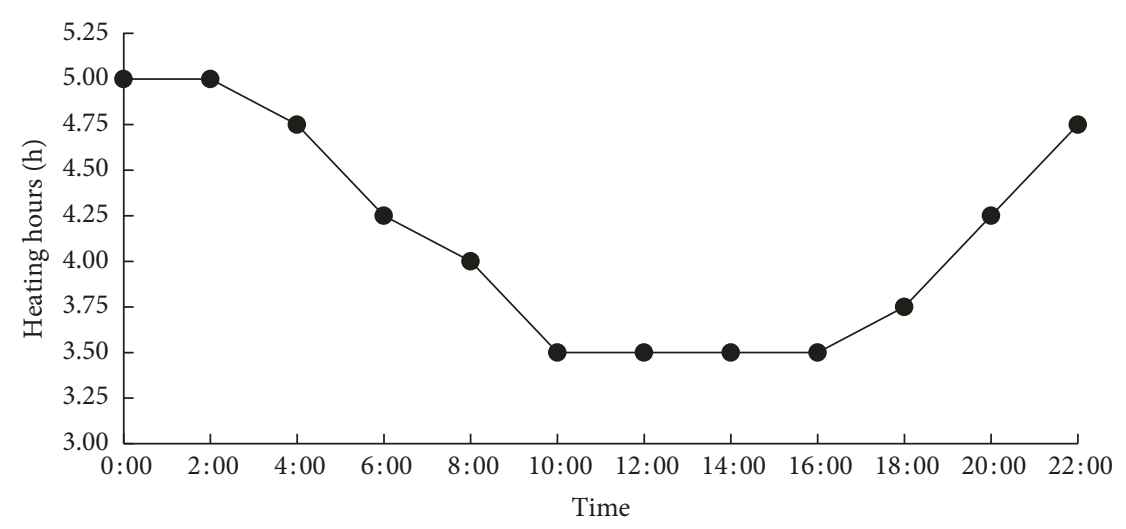

FIGURE 10: Heating hours at different points in time.

flow velocity $(0.55 \mathrm{~m} / \mathrm{s})$. Figure 11 shows the temperature timehistory curve of a certain point at the surface when the flow velocity increases from 0.6 to $2 \mathrm{~m} / \mathrm{s}$. The HSMP surface temperature increases slightly as flow velocity increases, which means that the flow velocity increase does not have a great impact on the heat transfer efficiency, identical to Ref. [34]. Therefore, the effect of flow velocity on the HSMP surface temperature is negligible, and the recommended magnitude is $0.6 \mathrm{~m} / \mathrm{s}$.
3.1.4. Effect of Pipe Embedded Depth. The pipe embedded depth represents the heat transfer distance from the pipe to the HSMP surface. Figure 12 shows the surface temperature distribution with the different $(7 \mathrm{~cm}, 9 \mathrm{~cm}, 11 \mathrm{~cm})$ pipe embedded depth and the pipe spacing $(15 \mathrm{~cm}$ and $30 \mathrm{~cm})$ after heating for $4.25 \mathrm{~h}$. As the pipe embedded depth increases, the heat transfer distance increase results in the surface temperature decrease, and the temperature curve is more smooth. It needs more time to transfer the energy of 


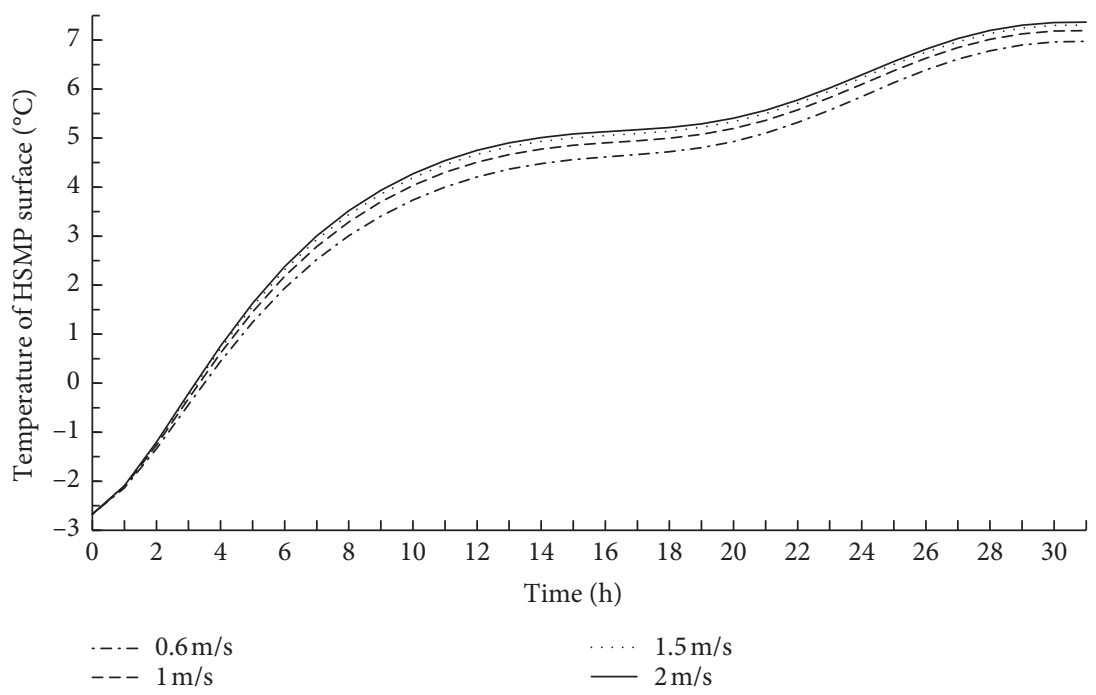

Figure 11: Temperature of the HSMP surface time-history curve.

heated pipes to the surface of HSMP as the pipe embedded depth increases. Therefore, the deeper the pipe embedded depth is, the less energy the surface of HSMP obtains. The reason is that the distance between $A$ point and the pipe has almost no difference with the distance between $B$ point and the pipe when the pipe embedded depth increases. Thus, the $\mathrm{A}$ and $\mathrm{B}$ point temperatures tend to be consistent and the temperature curve becomes flattening. In Figure 12(a), as the pipe embedded depth increases from $7 \mathrm{~cm}$ to $11 \mathrm{~cm}$, the $A$ and B point temperatures significantly descend, and the surface maximum temperature difference between two adjacent pipes decreases from $0.61^{\circ} \mathrm{C}$ to $0.11^{\circ} \mathrm{C}$. In Figure 12(b), as the pipe embedded depth increases from $7 \mathrm{~cm}$ to $11 \mathrm{~cm}$, the A point temperature obviously decreases, while the $\mathrm{B}$ point temperature has slight change, and the surface maximum temperature difference between two adjacent pipes decreases from $3.36^{\circ} \mathrm{C}$ to $1.45^{\circ} \mathrm{C}$. Results are in good agreement with the literature data [23]. It shows that appropriate decrease of pipe embedded depth and spacing can improve the surface temperature of HSMP and uniformity of the snowmelt process for the low temperature HSMP system.

3.1.5. Effect of Pipe Spacing. The pipe spacing is the horizontal distance between two adjacent pipes that affects the heat-transfer areas of the heat pipes. Figure 13 shows the surface temperature distribution with different $(10 \mathrm{~cm}$, $15 \mathrm{~cm}$, and $20 \mathrm{~cm}$ ) pipe spacing and pipe embedded depth $(7 \mathrm{~cm}$ and $11 \mathrm{~cm})$ after heating for $4.25 \mathrm{~h}$. As the pipe spacing increases, the heat-transfer area increase results in the surface temperature decrease, and the temperature curve becomes more steep. As the pipe spacing increases from $10 \mathrm{~cm}$ to $20 \mathrm{~cm}$, the surface maximum temperature difference between two adjacent pipes decreases from $1^{\circ} \mathrm{C}$ to $0.03^{\circ} \mathrm{C}$ at the pipe embedded depth of $7 \mathrm{~cm}$ and from $1.7^{\circ} \mathrm{C}$ to $0.14^{\circ} \mathrm{C}$ at the pipe embedded depth of $11 \mathrm{~cm}$, respectively. For a given size of HSMP, the narrower pipe spacing represents more number of pipes and smaller heat-transfer areas. As a result, the surface temperature increase and the temperature curve is more flattening. In other words, the larger pipe spacing presumes less number of pipes and larger heat-transfer areas. As mentioned in Refs. [35, 36], the narrower the pipe spacing is, the more uniform the surface temperature is. As shown in Figures 12 and 13, conclusions can be drawn that the the surface maximum temperature difference between two adjacent pipes become greater when the pipe embedded depth is shallower and the pipe spacing is wider.

It can be inferred that the pipe layouts have dominated influence on the uniformity of HSMP surface temperature. The shallower the pipe embedded depth and the narrower the pipe spacing, the higher the surface temperature and the lower the stripe distribution in the snowmelt process. Table 3 lists the numbers of hours for HSMP surface temperature below $0^{\circ} \mathrm{C}$ in different pipe layouts. The pipe embedded depth of $7 \mathrm{~cm}$ and pipe spacing of $10 \mathrm{~cm}$ were recommended for both convenience of construction and optimum snowmelt efficiency.

3.2. Thermal Response Analyses. In this section, the influence of pipe layouts on HSMP thermal responses was analysed and compared with the conventional pavement (without embedded pipes) under temperature load based on the 3D FE model. As the layer interface and contact interface between pipes and surrounding concrete almost have no effect on thermal responses [24, 37], the continuity condition is used at all interfaces. The boundary conditions for the sides and bottom of HSMP are simulated as fixed constraints.

3.2.1. Thermal Response of HSMP under Ambient Temperature Loads. For the sake of investigating the difference of thermal responses between HSMP and conventional pavement under ambient temperature loads, a 3D FE model of conventional pavement with the same size was modelled. The 


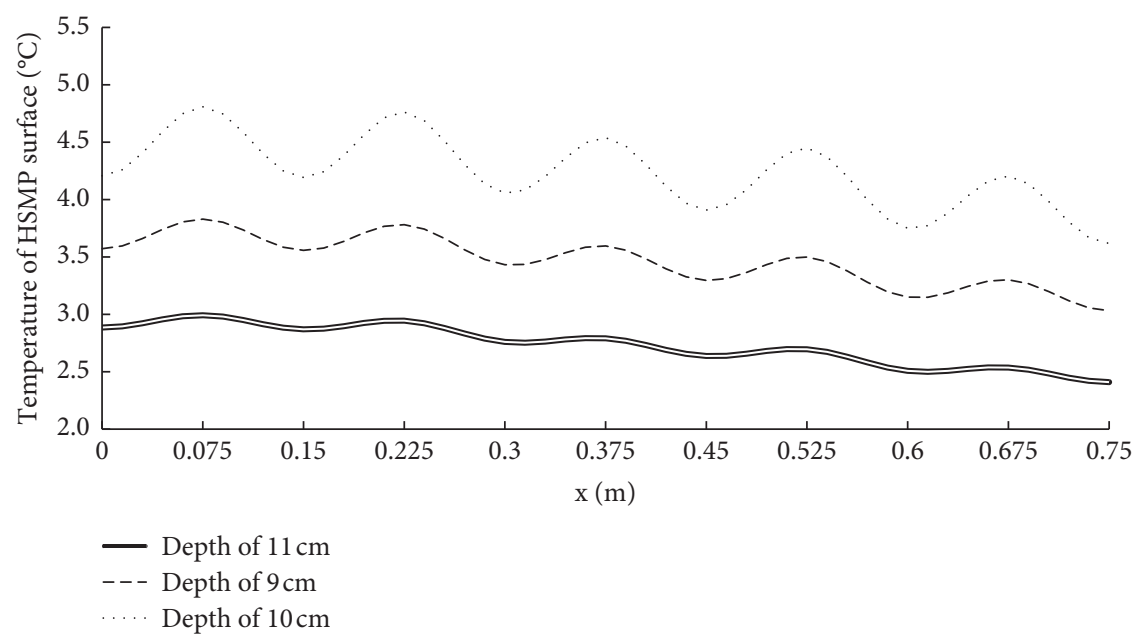

(a)

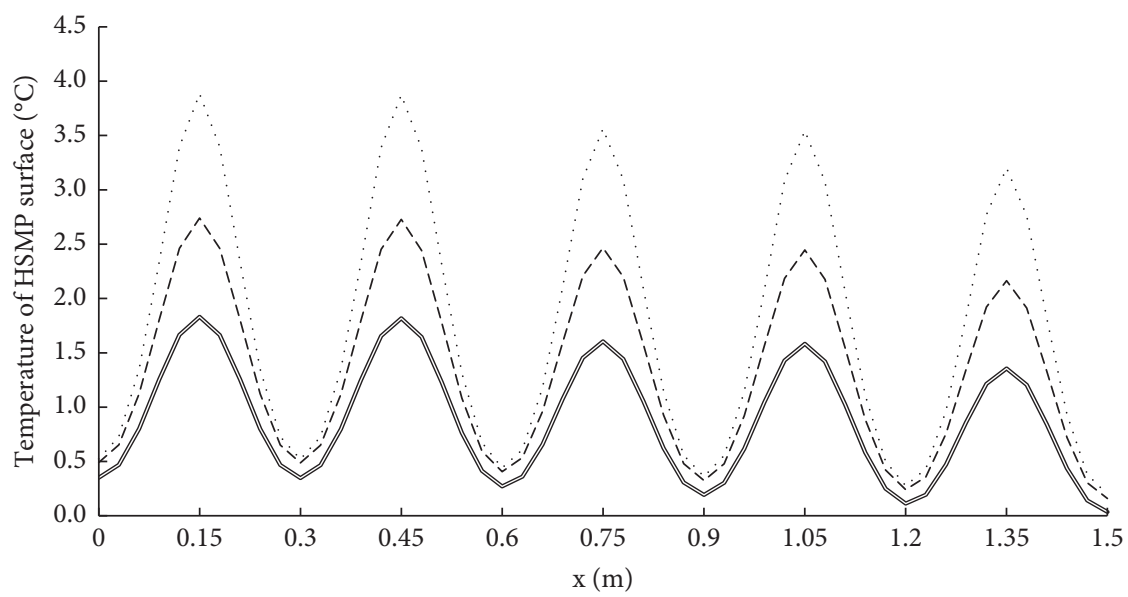

Depth of $11 \mathrm{~cm}$

--- Depth of $9 \mathrm{~cm}$

Depth of $7 \mathrm{~cm}$

(b)

Figure 12: Temperature of HSMP surface at the outlet section with different pipe embedded depths: (a) pipe spacing of $15 \mathrm{~cm}$; (b) pipe spacing of $30 \mathrm{~cm}$.

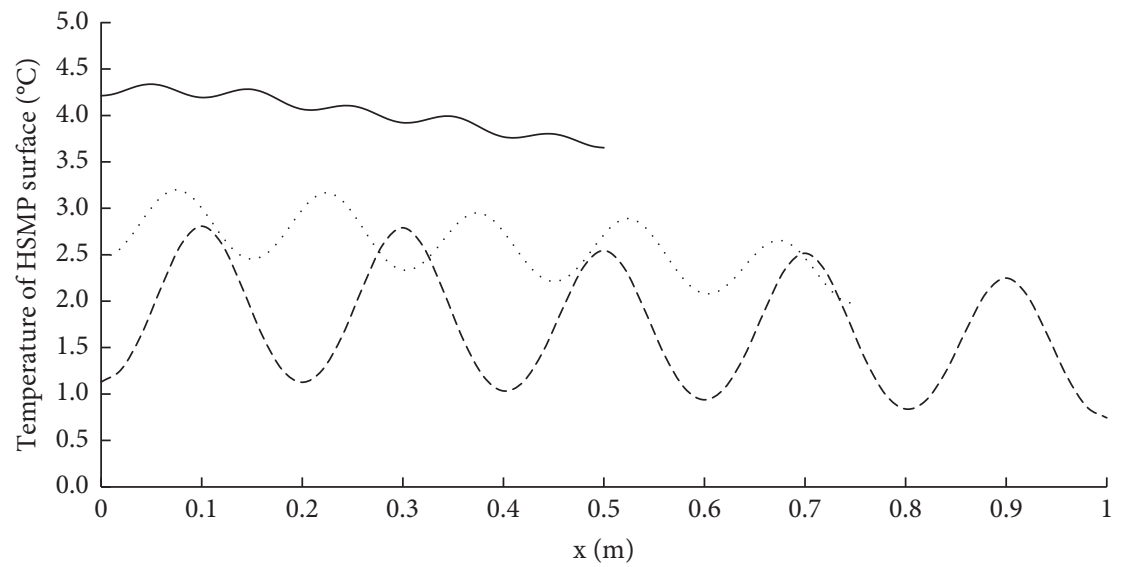

- Spacing of $10 \mathrm{~cm}$ Spacing of $15 \mathrm{~cm}$

-- Spacing of $20 \mathrm{~cm}$

(a)

FIgUre 13: Continued. 


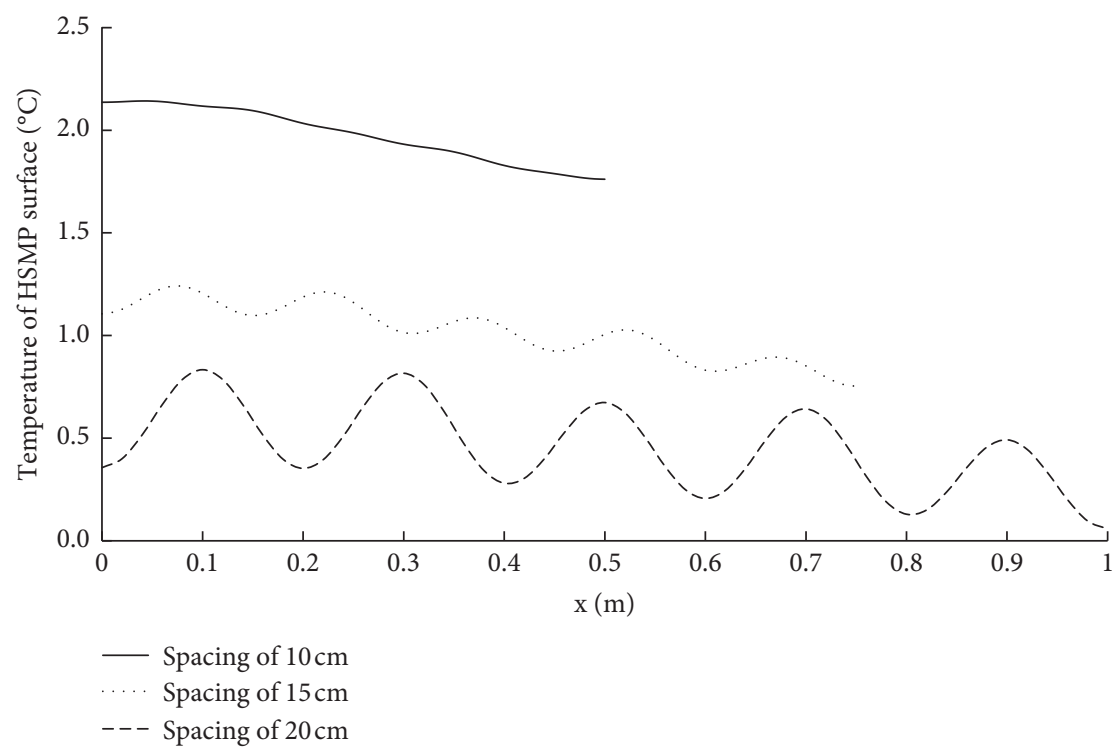

(b)

FIGURE 13: Temperature of the HSMP surface at the outlet section with different pipe spacing: (a) pipe embedded depth of $7 \mathrm{~cm}$; (b) pipe embedded depth of $11 \mathrm{~cm}$.

TABLE 3: The numbers of hours for HSMP surface temperature below $0^{\circ} \mathrm{C}$.

\begin{tabular}{lccc}
\hline $\begin{array}{l}\text { Spacing }(\mathrm{cm}) \\
\text { Time }(\mathrm{h})\end{array}$ & 10 & 15 & 20 \\
Depth $(\mathrm{cm})$ & 1 & 1.25 & 1.75 \\
\hline 7 & 1.25 & 1.5 & 2 \\
9 & 1.5 & 1.75 & 2.25 \\
11 &
\end{tabular}

temperature distribution of pavement at 6:00 is considered as temperature loads. The maximum principle tensile stress is generated at the bottom of the conventional pavement under a positive temperature gradient load, and the magnitude of $\mathrm{AL}$ and $\mathrm{CL}$ are $0.4 \mathrm{MPa}$ and 2.2 $\mathrm{MPa}$, respectively. However, the HSMP stress distribution features (e.g., maximum stress position, distribution shape, and magnitude) are evidently different with the conventional pavement. As shown in Figure 14, the stress distribution shape of HSMP (the pipe spacing of $15 \mathrm{~mm}$ and the pipe embedded depth of $7 \mathrm{~mm}$ ) is approximate to the diffraction fringe. The maximum principle tensile stress is occurred at the contact interface between pipes and surrounding concrete, and the magnitude is greater than that of the conventional pavement. The magnitude of $\mathrm{AL}$ and $\mathrm{CL}$ are $0.43 \mathrm{MPa}$ and $2.78 \mathrm{MPa}$, respectively. The results are in good agreement with Refs. $[24,38]$. Due to the greater line expansion coefficient, the shrinkage deformation of pipes is greater than that of concrete. The concrete around pipes is pulled by the pipes, due to which the greater tensile stress is occurred. As shown in Figure 15, the maximum principle stress and vertical displacement of the pipe are the greatest at the bottom and the top, respectively, due to the free boundary of the HSMP surface.

Table 4 and 5 show the maximum principle stress of HSMP with different pipe layouts under ambient temperature loads. The pipe shrinkage results in the special thermal responses of HSMP. The thermal response of CL is more significantly influenced than that of AL due to the pipe embedded. With the increase of pipe embedded depth and pipe spacing, the maximum principle stress of HSMP has little influence and is in accordance with Ref. [39].

3.2.2. Thermal Response of HSMP with Fluid Circulation. In this section, the thermal response of HSMP is simulated when HSMP suffers the ambient temperature (at 6:00) and fluid circulation $\left(15^{\circ} \mathrm{C}\right)$. In Figure 16 , the maximum principle compressive stress and principle tensile stress of the concrete are generated on the contact interface of the top and bottom of the pipe and of the left and right of the pipe, respectively. Due to the pipe thermal expansion, the concrete above the top or below the bottom of the pipe and the concrete between adjacent pipes are subjected to pressure and tension, respectively. It can be found from Figure 16(b) that a smaller maximum principle tensile stress (1.523 MPa) of HSMP with fluid circulation is induced and the magnitude reduces to $54.8 \%$ comparing to conventional pavement. As reported in Ref. [24], the thermal stress of HSMP is attributed to the heat transfer and exchange interaction between fluid circulation and concrete.

Figure 17 illustrates the maximum principle stress and vertical displacement of the pipe. Due to the steep temperature gradient of the pipe and the weaker constraint of concrete above the pipe, the extreme values are at the pipe bottom and the pipe top, respectively. Compared with Figure 15, the stress and displacement distribution of the pipe are obviously different and HSMP with fluid circulation is in a state of "internal dilatation and external shrinkage." 

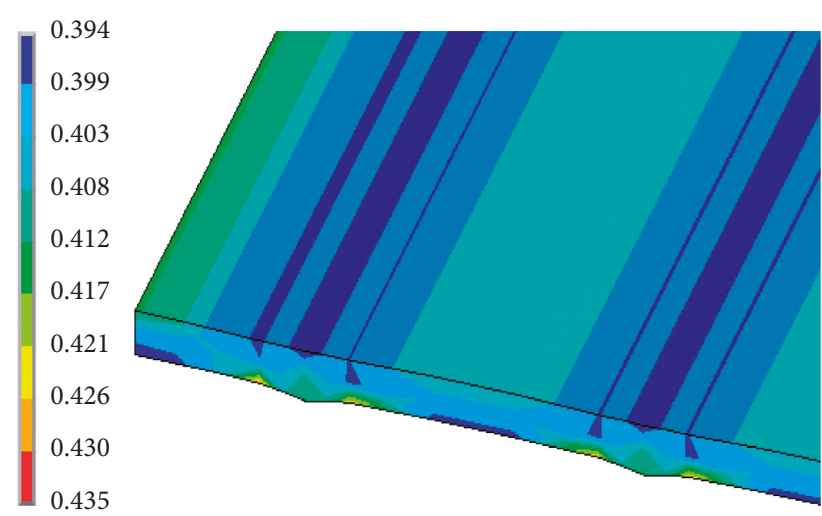

(a)

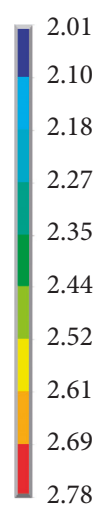

2.78

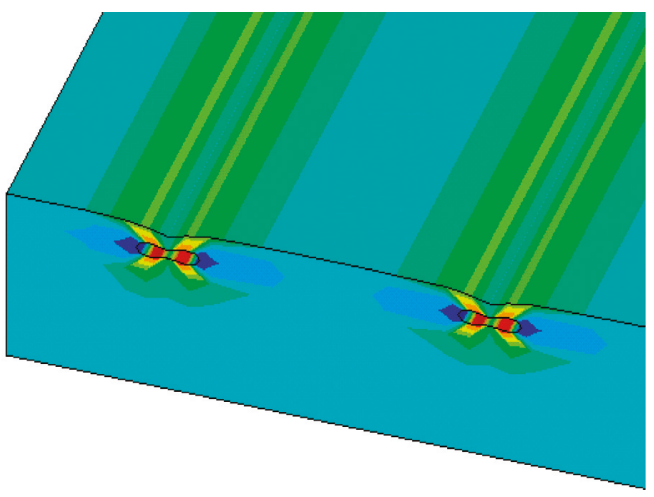

(b)

Figure 14: Maximum principle stress distribution (MPa) of HSMP under ambient temperature loads: (a) AL; (b) CL.
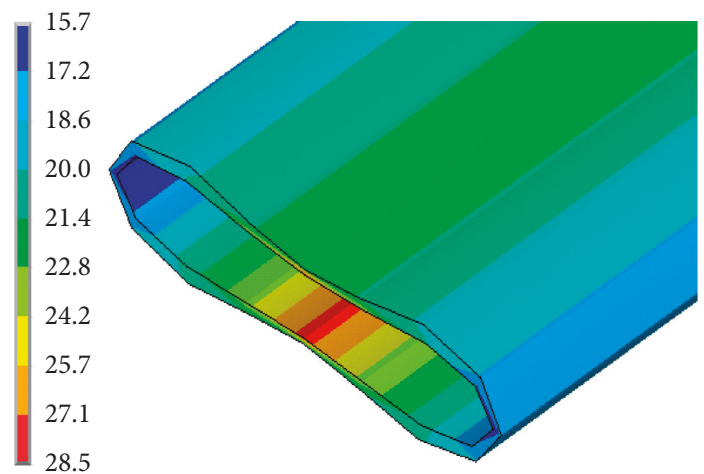

(a)

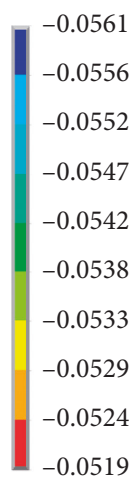

$-0.0519$

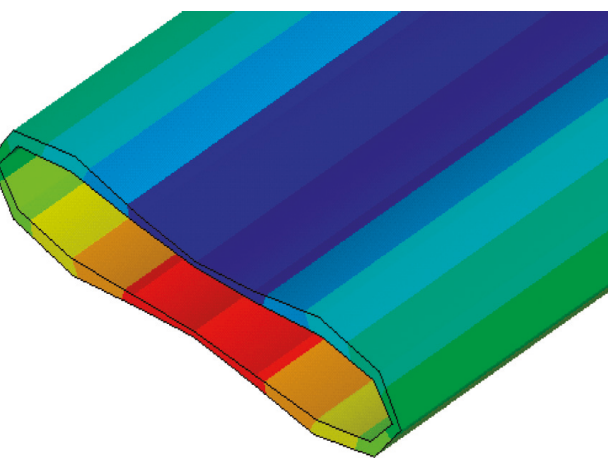

(b)

FIgURE 15: Thermal responses of the pipe under ambient temperature loads: (a) maximum principle stress distribution (MPa); (b) vertical displacement $(\mathrm{mm})$.

TABLE 4: Maximum principle stress extreme values of HSMP under ambient temperature loads (pipe spacing of $15 \mathrm{~cm}$ ).

\begin{tabular}{lccc}
\hline \multirow{2}{*}{ Layers } & Depth $(\mathrm{cm})$ & \multicolumn{2}{c}{$\begin{array}{c}\text { Maximum principle } \\
\text { stress }(\mathrm{MPa})\end{array}$} \\
& 7 & Min & Max \\
\hline \multirow{3}{*}{ AL } & 9 & 0.393 & 0.431 \\
& 11 & 0.397 & 0.407 \\
& 7 & 0.397 & 0.404 \\
\hline \multirow{3}{*}{ CL } & 9 & 2.012 & 2.782 \\
& 11 & 2.032 & 2.743 \\
& 7 & 2.043 & 2.734 \\
\hline \multirow{3}{*}{ Pipe } & 9 & 15.741 & 28.512 \\
& 11 & 16.123 & 27.632 \\
& & 16.224 & 27.714 \\
\hline
\end{tabular}

In Table 6, with the increase of pipe embedded depth, the maximum principle tensile stress and the maximum principle compressive stress decreases and increases, respectively. The deeper the pipe embedded is, the greater the constrain is and the greater the compressive stress of the pipe is. It implies that the chance of thermal shrinkage cracks decreases with increasing the pipe embedded depth.
TABLE 5: Maximum principle stress extreme values of HSMP under ambient temperature loads (pipe embedded depth of $7 \mathrm{~cm}$ ).

\begin{tabular}{lccc}
\hline \multirow{2}{*}{ Layers } & Spacing $(\mathrm{cm})$ & \multicolumn{2}{c}{$\begin{array}{c}\text { Maximum principle } \\
\text { stress }(\mathrm{MPa})\end{array}$} \\
& & Min & Max \\
\hline \multirow{3}{*}{$\mathrm{AL}$} & 10 & 0.392 & 0.424 \\
& 15 & 0.393 & 0.431 \\
& 20 & 0.393 & 0.434 \\
$\mathrm{CL}$ & 10 & 2.011 & 2.713 \\
& 15 & 2.012 & 2.782 \\
& 20 & 2.012 & 2.791 \\
\hline \multirow{3}{*}{ Pipe } & 10 & 15.821 & 27.844 \\
& 15 & 15.741 & 28.521 \\
& 20 & 15.691 & 28.712 \\
\hline
\end{tabular}

In Table 7, with the increase of the pipe spacing, the maximum principle stress increases. For a given size of HSMP, the larger pipe spacing represents less number of pipes and greater temperature gradients, which increases the thermal shrinkage cracking risk. Therefore, the deeper and narrower the pipe is embedded, the smaller the principle tensile stress of HSMP is. Overall, heated pipes 


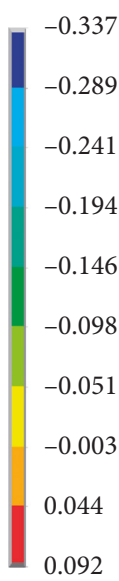

0.092

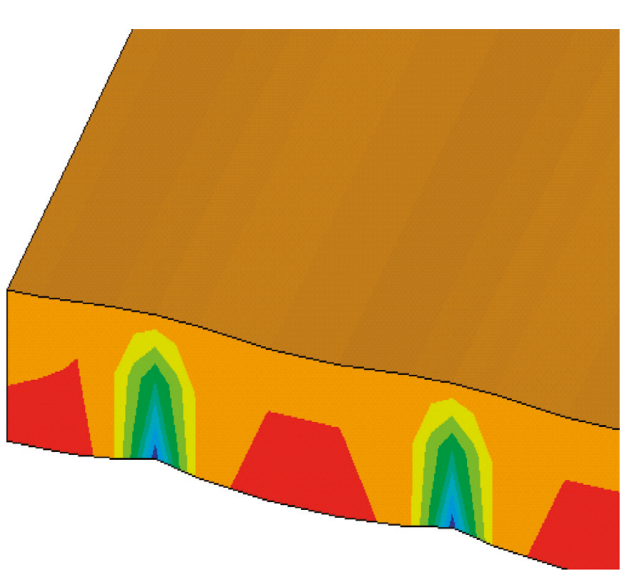

(a)

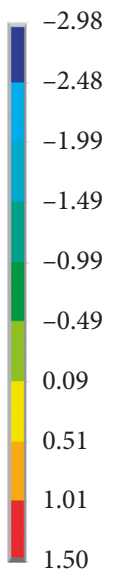

.50

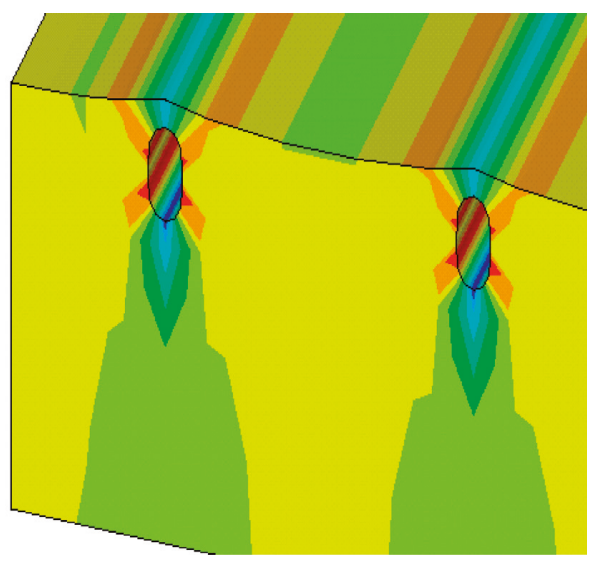

(b)

FIgURE 16: Maximum principle stress distribution (MPa) of HSMP with fluid circulation: (a) AL; (b) CL.
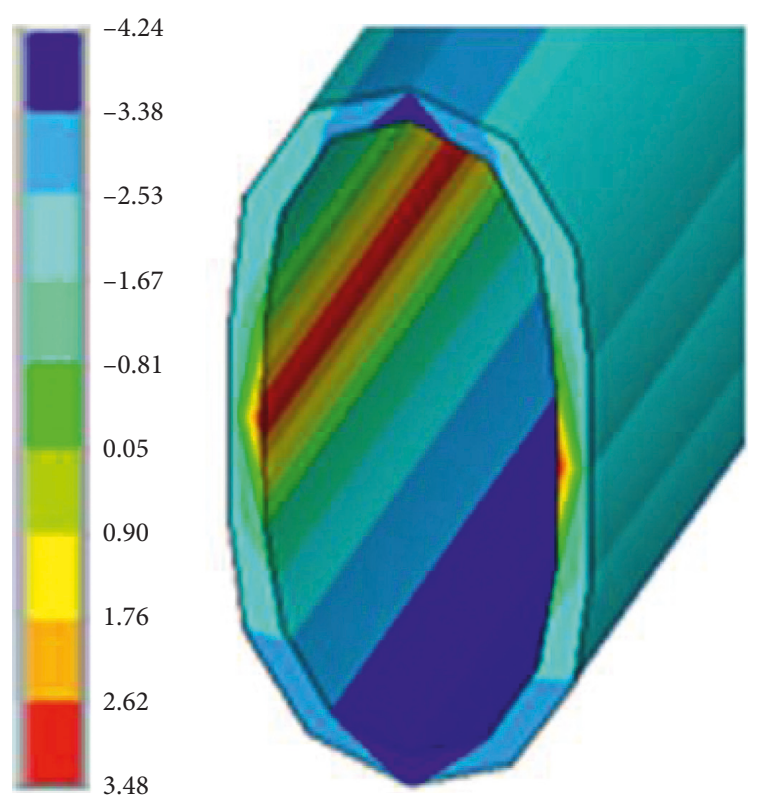

(a)

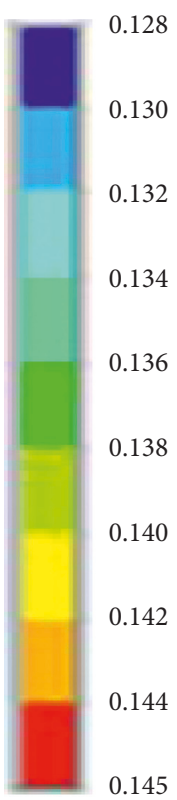

0.145

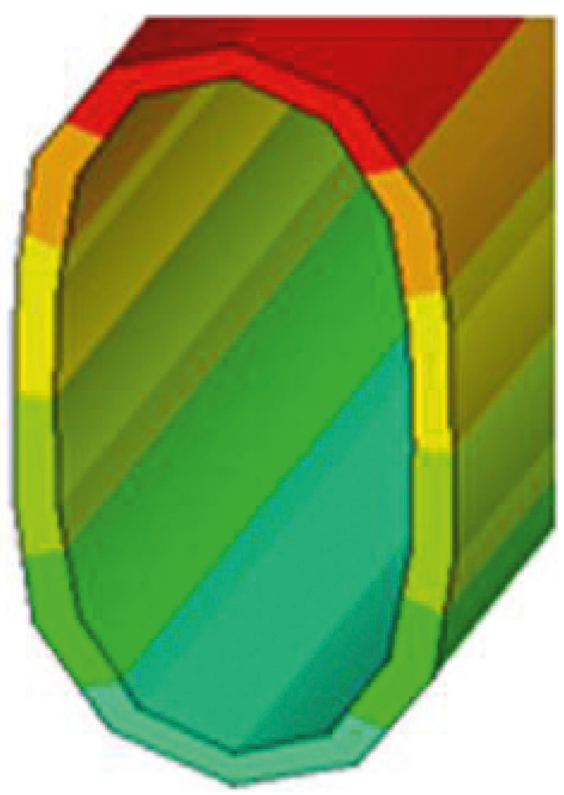

(b)

FIGURE 17: Thermal responses of the pipe with fluid circulation: (a) maximum principle stress distribution (MPa); (b) vertical displacement (mm).

TABLE 6: Maximum principle stress extreme values of HSMP with fluid circulation (pipe spacing of $15 \mathrm{~cm}$ ).

\begin{tabular}{|c|c|c|c|}
\hline \multirow{2}{*}{ Layers } & \multirow{2}{*}{ Depth $(\mathrm{cm})$} & \multicolumn{2}{|c|}{ Maximum principle stress $(\mathrm{MPa})$} \\
\hline & & Min & $\operatorname{Max}$ \\
\hline \multirow{3}{*}{$\mathrm{AL}$} & 7 & -0.336 & 0.091 \\
\hline & 9 & -0.113 & 0.063 \\
\hline & 11 & -0.654 & 0.042 \\
\hline \multirow{3}{*}{ CL } & 7 & -2.983 & 1.523 \\
\hline & 9 & -3.134 & 1.132 \\
\hline & 11 & -3.143 & 1.073 \\
\hline \multirow{3}{*}{ Pipe } & 7 & -4.244 & 3.484 \\
\hline & 9 & -4.322 & 3.072 \\
\hline & 11 & -4.412 & -1.134 \\
\hline
\end{tabular}


TABLE 7: Maximum principle stress extreme values of HSMP with fluid circulation (pipe embedded depth of $7 \mathrm{~cm}$ ).

\begin{tabular}{lccc}
\hline \multirow{2}{*}{ Layers } & & \multicolumn{2}{c}{$\begin{array}{c}\text { Maximum principle } \\
\text { stress }(\mathrm{MPa})\end{array}$} \\
& Spacing $(\mathrm{cm})$ & Min & Max \\
\hline \multirow{3}{*}{$\mathrm{AL}$} & 10 & -0.291 & 0.098 \\
& 15 & -0.336 & 0.091 \\
& 20 & -0.337 & 0.122 \\
$\mathrm{CL}$ & 10 & -2.832 & 1.274 \\
& 15 & -2.983 & 1.523 \\
\multirow{3}{*}{ Pipe } & 20 & -3.042 & 1.773 \\
& 10 & -4.123 & 1.551 \\
& 15 & -4.244 & 3.484 \\
& 20 & -4.321 & 5.672 \\
\hline
\end{tabular}

can effectively prevent thermal shrinkage cracks and prolong service life of HSMP. Considering the snowmelt efficiency, the pipe embedded depth of $7 \mathrm{~cm}$ and pipe spacing of $10 \mathrm{~cm}$ were proposed.

\section{Conclusions}

For the bridge deck hydronic snow melting system utilizing low temperature water, a 3D FE model of HSMP was built. Influence factors on the temperature distribution and thermal responses of HSMP were studied, respectively. The following conclusions are drawn from this study:

(1) The 3D FE model of HSMP based on the thermalfluid coupling method was developed to solve the heat transmission and thermal responses of HSMP.

(2) Particularly, the insulation, start time of heating, pipe embedded depth, and pipe spacing have significant impacts on the snowmelt performance, while the flow velocity has a slight influence.

(3) The pipe layout has little impact on the thermal response of HSMP under ambient temperature loads. However, the principle tensile stress and the chance of thermal shrinkage cracks decreases for HSMP with fluid circulation as the pipe embedded depth is deeper and the pipe spacing is narrower.

(4) The pipe embedded depth of $7 \mathrm{~cm}$ and pipe spacing of $10 \mathrm{~cm}$ for HSMP with the inlet fluid temperature of $15^{\circ} \mathrm{C}$ are recommended for both optimum snowmelt efficiency and the reduction of thermal shrinkage cracking risk.

\section{Data Availability}

The data used to support the findings of this study are included within the supplementary information files.

\section{Conflicts of Interest}

The authors declare that there are no conflicts of interest regarding the publication of this paper.

\section{Acknowledgments}

This work was supported by the Doctoral Fund of the Ministry of Education of China (grant no. 20130205110014), the Natural Science Basic Research Plan in Shaanxi Province of China (grant no. 2014JM1005), the Science and Technology Program of the Department of Transportation in Shaanxi Province of China (grant no. 13-16k), and the Science and Technology Planning Project in Henan Province of China (grant no. 182102311091).

\section{Supplementary Materials}

In the "insulated bottom" folder, two text files are, respectively, the command-flow of the 3D FE model of HSMP (pipe spacing of $30 \mathrm{~mm}$ and pipe embedded depth of $11 \mathrm{~cm}$ ) and conventional pavement (without embedded pipes) with the insulation at the bottom. In the "noninsulated bottom" folder, two text files are, respectively, the command-flow of the 3D FE model of HSMP (pipe spacing of $30 \mathrm{~mm}$ and pipe embedded depth of $11 \mathrm{~cm}$ ) and conventional pavement (without embedded pipes) without the insulation at the bottom. In the "spacing of $10 \mathrm{~mm}$ " folder, three text files are, respectively, the command-flow of the 3D FE model of HSMP with pipe spacing of $10 \mathrm{~mm}$ and different pipe embedded depths $(7 \mathrm{~mm}, 9 \mathrm{~mm}$, and $11 \mathrm{~cm})$. In the "spacing of $15 \mathrm{~mm}$ " folder, three text files are, respectively, the command-flow of the 3D FE model of HSMP with pipe spacing of $15 \mathrm{~mm}$ and different pipe embedded depths $(7 \mathrm{~mm}, 9 \mathrm{~mm}$, and $11 \mathrm{~cm})$. In the "spacing of $20 \mathrm{~mm}$ " folder, three text files are, respectively, the command-flow of the $3 \mathrm{D}$ FE model of HSMP with pipe spacing of $20 \mathrm{~mm}$ and different pipe embedded depths $(7 \mathrm{~mm}, 9 \mathrm{~mm}$, and $11 \mathrm{~cm})$. In the "spacing of $30 \mathrm{~mm}$ " folder, three text files are, respectively, the command-flow of the 3D FE model of HSMP with pipe spacing of $30 \mathrm{~mm}$ and different pipe embedded depths $(7 \mathrm{~mm}, 9 \mathrm{~mm}$, and $11 \mathrm{~cm})$. (Supplementary Materials)

\section{References}

[1] H. Xu, D. Wang, Y. Tan, J. Zhou, and M. Oeser, "Investigation of design alternatives for hydronic snow melting pavement systems in China," Journal of Cleaner Production, vol. 170, pp. 1413-1422, 2018.

[2] X. Liu, S. J. Rees, and J. D. Spitler, "Modeling snow melting on heated pavement surfaces. Part I: model development," Applied Thermal Engineering, vol. 27, no. 5-6, pp. 1115-1124, 2007.

[3] H. Wang, C. Thakkar, X. Chen, and S. Murrel, "Life-cycle assessment of airport pavement design alternatives for energy and environmental impacts," Journal of Cleaner Production, vol. 133, pp. 163-171, 2016.

[4] J. Carmona, P. Garcés, and M. A. Climent, "Efficiency of a conductive cement-based anodic system for the application of cathodic protection, cathodic prevention and electrochemical chloride extraction to control corrosion in reinforced concrete structures," Corrosion Science, vol. 96, pp. 102-111, 2015.

[5] L. Fay and X. Shi, "Environmental impacts of chemicals for snow and ice control: state of the knowledge," Water, Air, \& Soil Pollution, vol. 223, no. 5, pp. 2751-2770, 2012. 
[6] A. Balbay and M. Esen, "Temperature distributions in pavement and bridge slabs heated by using vertical groundsource heat pump systems," Acta Scientiarum. Technology, vol. 35, no. 4, pp. 677-685, 2013.

[7] A. Balbay and M. Esen, "Experimental investigation of using ground source heat pump system for snow melting on pavements and bridge decks," Scientific Research and Essays, vol. 5, no. 24, pp. 3955-3966, 2010.

[8] H. Wang, L. Liu, and Z. Chen, "Experimental investigation of hydronic snow melting process on the inclined pavement," Cold Regions Science and Technology, vol. 63, no. 1-2, pp. 44-49, 2010.

[9] Y. Lai, Y. Liu, and D. Ma, "Automatically melting snow on airport cement concrete pavement with carbon fiber grille," Cold Regions Science and Technology, vol. 103, pp. 57-62, 2014.

[10] K. Liu, S. Huang, C. Jin, H. Xie, and F. Wang, "Prediction models of the thermal field on ice-snow melting pavement with electric heating pipes," Applied Thermal Engineering, vol. 120, pp. 269-276, 2017.

[11] J. Chen, M. Zhang, H. Wang, and L. Li, "Evaluation of thermal conductivity of asphalt concrete with heterogeneous microstructure," Applied Thermal Engineering, vol. 84, pp. 368-374, 2015.

[12] J. Gomis, O. Galao, V. Gomis, E. Zornoza, and P. Garcés, "Self-heating and deicing conductive cement. Experimental study and modeling," Construction and Building Materials, vol. 75, pp. 442-449, 2015.

[13] H. Wang and Z. Chen, "Study of critical free-area ratio during the snow-melting process on pavement using low-temperature heating fluids," Energy Conversion and Management, vol. 50, no. 1, pp. 157-165, 2009.

[14] T. N. Adlam, Snow Melting; Design, Installation and Control of Systems for Melting Snow, Vol. 224, The Industrial Press, New York, NY, USA, 1950.

[15] P. Pan, S. Wu, Y. Xiao, and G. Liu, "A review on hydronic asphalt pavement for energy harvesting and snow melting," Renewable and Sustainable Energy Reviews, vol. 48, pp. 624634, 2015.

[16] X. Liu, S. J. Rees, and J. D. Spitler, "Modeling snow melting on heated pavement surfaces. part ii: experimental validation," Applied Thermal Engineering, vol. 27, no. 5-6, pp. 1125-1131, 2007.

[17] S. J. Rees, J. D. Spitler, and X. Xiao, "Transient analysis of snow-melting system performance," ASHRAE Transactions, vol. 108, no. 2, pp. 406-423, 2002.

[18] X. Liu, S. J. Rees, and J. D. Spitler, "Simulation of a geothermal bridge deck anti-icing system and experimental validation," in Proceedings of the Transportation Research Board 82nd Annual Meeting, pp. 12-16, Washington, DC January, January 2003.

[19] A. D. Chiasson, J. D. Spitler, S. J. Rees, and M. D. Smith, “A model for simulating the performance of a pavement heating system as a supplemental heat rejecter with closed-loop ground-source heat pump systems," Journal of Solar Energy Engineering, vol. 122, no. 4, pp. 183-191, 2000.

[20] X. Liu, "Development and Experimental Validation of Simulation of Hydronic Snow Melting Systems for Bridges," Ph.D dissertation, Oklahoma State University, Stillwater, OK, USA, 2005.

[21] J. Josef and A. Z. Bijan, "Modeling the thermal performance of low temperature hydronic heated pavements," Cold Regions Science Technology, vol. 161, pp. 81-90, 2019.

[22] K. Li and N. Hong, "Dynamic heat load calculation of a bridge anti-icing system," Applied Thermal Engineering, vol. 128, pp. 198-203, 2018.
[23] M. R. A. Van Vliet, C. A. P. M. Van Gurp, A. H. De Bondt, and W. T. Van Bijsterveld, "Structural viability of shallow depth hollow systems in airfield pavements," in Proceedings of the 1st European airport pavement workshop, Amsterdam, Netherlands, May 2005.

[24] Y. Q. Tan, Y. K. Fu, Y. L. Li, and C. Zhang, "Responses of snow-melting airfield rigid pavement under aircraft loads and temperature loads and their coupling effects," Transportation Geotechnics, vol. 14, pp. 107-116, 2018.

[25] Y. Duan, Z. L. Xiang, X. L. Chang, and X. H. Liu, "Comparative analysis of pipe cooling in mass concrete using thermal-fluid coupling method and equivalent method based on FEM," Engineering Journal Wuhan University, vol. 43, no. 6, pp. 703-707, 2010.

[26] T. L. Bergman, F. P. Incropera, D. P. DeWitt, and A. S. Lavine, Fundamentals of Heat and Mass Transfer, John Wiley \& Sons, Hoboken, NJ, USA, 2011.

[27] F. W. Dittus and L. M. K. Boelter, "Heat transfer in automobile radiators of the tubular type," International Communications in Heat and Mass Transfer, vol. 12, no. 1, pp. 3-22, 1985.

[28] W. H. McAdams, Heat Transmission, McGraw-Hill, New York, NY, USA, 1954.

[29] Z. R. Yan, "Analysis of the temperature field in layered pavement system," Journal of Tongji University, vol. 3, pp. 76-85, 1984.

[30] W. Y. Liu, D. Y. Huang, and Y. J. Hua, "Probe into test method of heat convection coefficient of concrete," Journal Building Materials, vol. 2, pp. 232-235, 2004.

[31] L. Feng, L. Wang, and W. Du, "Experimental research on temperature field distribution characteristics of asphalt deck pavement," Journal of Inner Mongolia University Technology, vol. 36, no. 6, pp. 113-118, 2014.

[32] H. Liu, P. Maghoul, and H. M. Holländer, "Sensitivity analysis and optimum design of a hydronic snow melting system during snowfall," Physics and Chemistry of the Earth, Parts A/B/A, 2019.

[33] W. J. Hu, "Fundamental study of snow-melting on bridge deck based on ground source heat pumps," Master thesis, Harbin Institute of Technology, Harbin, China, 2006.

[34] R. B. Mallick, B. L. Chen, and S. Bhowmick, "Harvesting heat energy from asphalt pavements: development of and comparison between numerical models and experiment," International Journal of Sustainable Engineering, vol. 5, no. 2, pp. 159-169, 2011.

[35] Z. Fu, X. C. Wang, and K. Q. Lu, "Influence of pipe-burying mode on hydrothermal snow melting of bridge decks," Journal of South China University Technology, vol. 42, no. 5, pp. 90-96, 2014.

[36] C. Zhang, Y. Q. Tan, F. C. Chen, Q. Ye, and H. N. Xu, "Longterm thermal analysis of an airfield-runway snow-melting system utilizing heat-pipe technology," Energy Conversion and Management, vol. 186, pp. 473-486, 2019.

[37] L. Feng, L. Wang, and W. Du, "Finite element analysis of bridge deck pavement temperature stress," Journal of Inner Mongolia University Technology, vol. 33, no. 3, pp. 227-234, 2017.

[38] K. Liu, "Study on cement concrete pavement of snow melting and deicing," Ph.D dissertation, Chang'an University, Xi'an, China, 2010.

[39] Z. Fu, X. C. Wang, and K. Q. Lu, "Effects of snowmelt system with hydrothermal buried pipes on bridge paving," Journal of Chang'an University (Natural Science Edition), vol. 34, no. 4, pp. 70-76, 2014. 


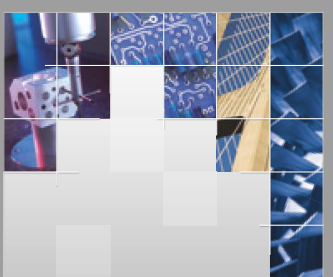

\section{Enfincering}
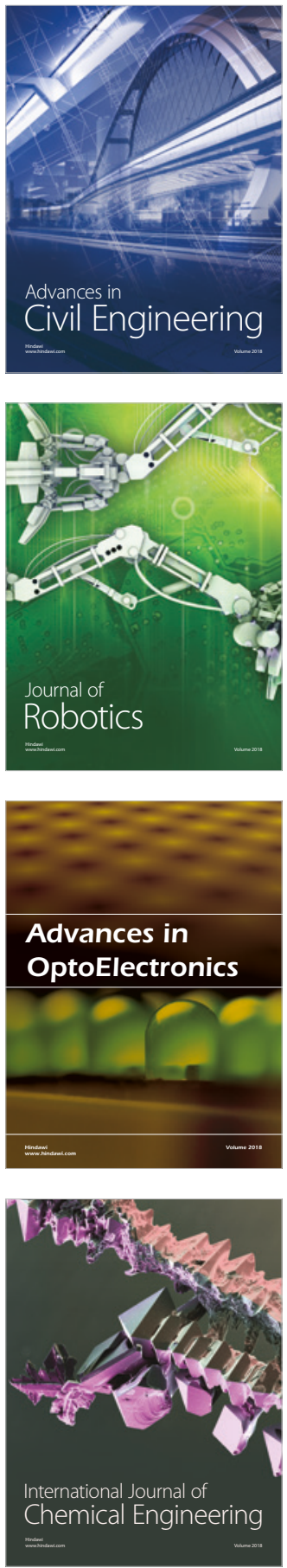

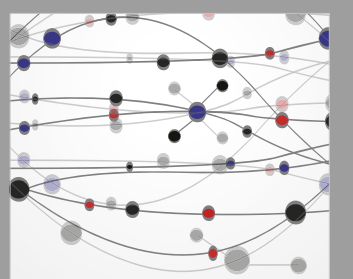

\section{Rotating \\ Machinery}

The Scientific World Journal

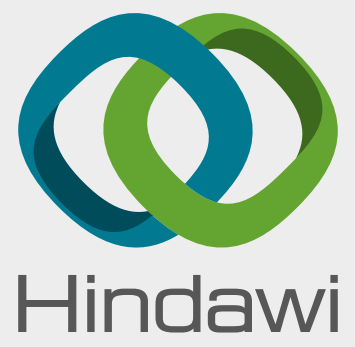

Submit your manuscripts at

www.hindawi.com
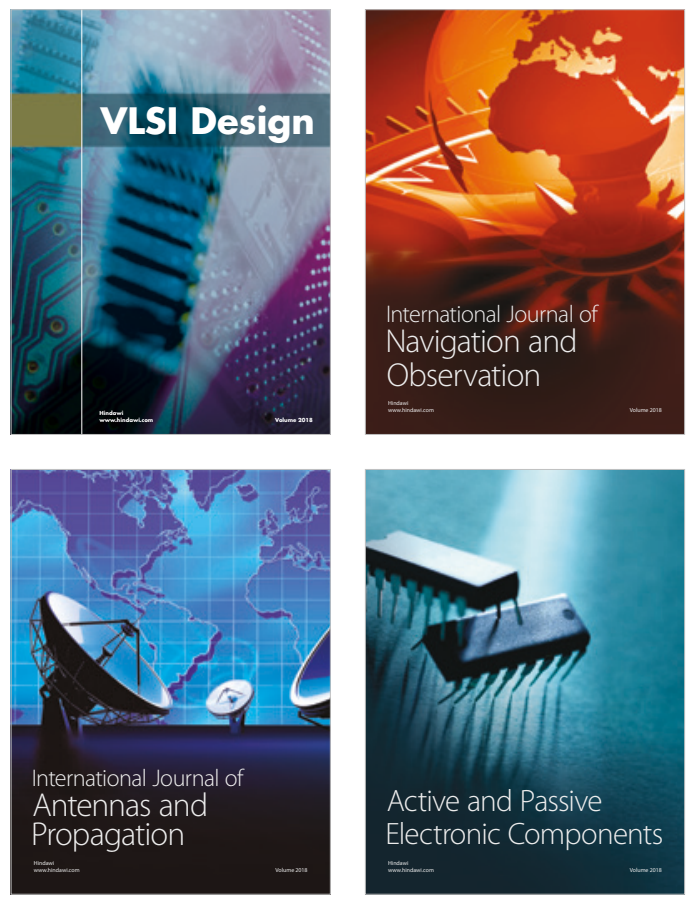
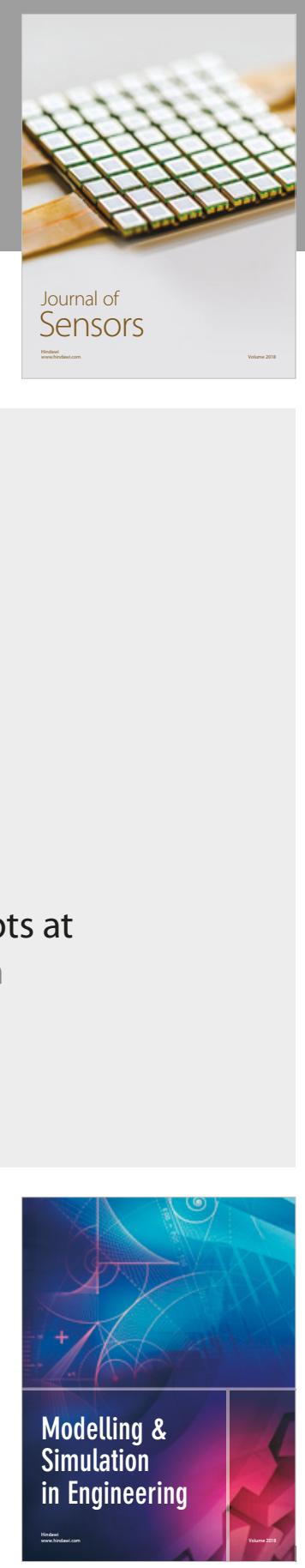

\section{Advances \\ Multimedia}
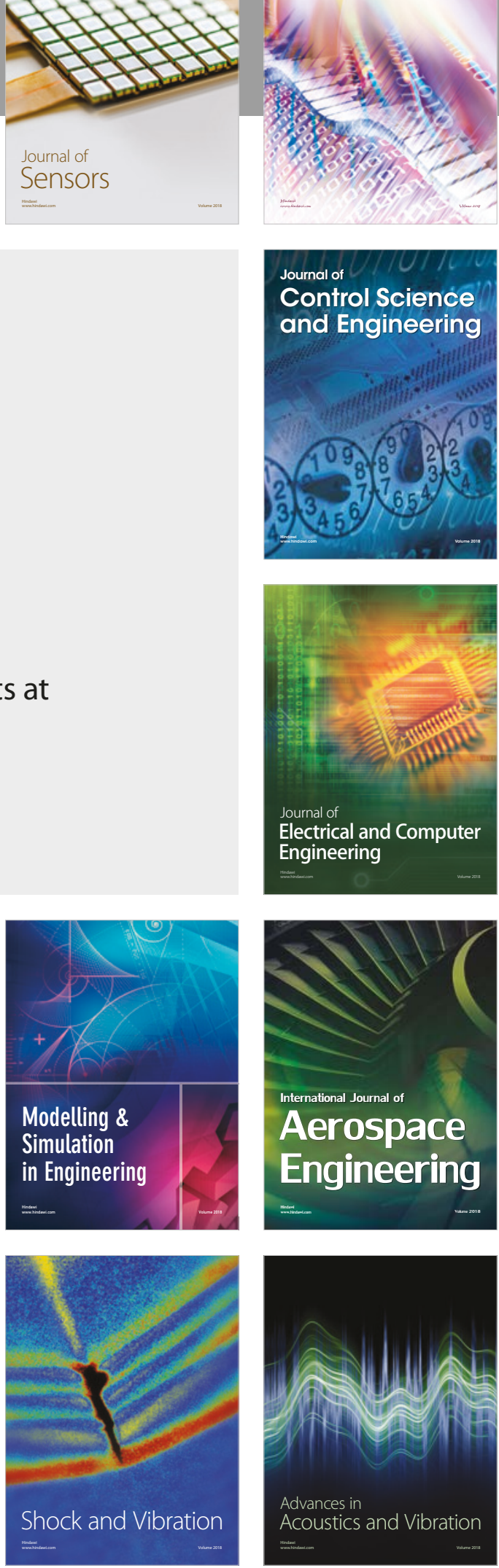